Article

\title{
Tantalum Alloy Welding: Does the Thermal Cycle Influence the Microstructure?
}

\author{
Antonio Bernardo Sánchez ${ }^{1, *(D)}$, Álvaro Presno Vélez ${ }^{2} \mathbb{D}$, Tomás Fernández-Columbié ${ }^{3}$, \\ Isnel Rodríguez-Gonzalez ${ }^{3}{ }^{(\mathbb{D}}$, Ledennis Suárez Torres ${ }^{3}$, Laura Álvarez de Prado ${ }^{1}$ \\ and Marta Menéndez Fernández ${ }^{1}$
}

Citation: Bernardo Sánchez, A.; Presno Vélez, Á.; Fernández-

Columbié, T.; Rodríguez-Gonzalez, I.; Suárez Torres, L.; Álvarez de Prado, L.; Menéndez Fernández, M. Tantalum Alloy Welding: Does the Thermal Cycle Influence the Microstructure? Appl. Sci. 2022, 12, 1440. https://doi.org/10.3390/ app12031440

Academic Editors: Jacek Tomków and Guijun Bi

Received: 20 December 2021

Accepted: 26 January 2022

Published: 28 January 2022

Publisher's Note: MDPI stays neutral with regard to jurisdictional claims in published maps and institutional affiliations.

Copyright: (C) 2022 by the authors. Licensee MDPI, Basel, Switzerland. This article is an open access article distributed under the terms and conditions of the Creative Commons Attribution (CC BY) license (https:// creativecommons.org/licenses/by/ $4.0 /)$.
1 Department of Mining Technology, Topography and Structures, University of León, 24071 León, Spain; laura.alvarez@unileon.es (L.Á.d.P.); marta.menendez@unileon.es (M.M.F.)

2 Department of Mathematics, University of Oviedo, 33007 Oviedo, Spain; a.presno.velez@gmail.com

3 Department of Mechanics, Moa University, Moa, 83330 Holguin, Cuba; tfernandez@ismm.edu.cu (T.F.-C.); irgonzalez@ismm.edu.cu (I.R.-G.); 1storres@ismm.edu.cu (L.S.T.)

* Correspondence: abers@unileon.es; Tel.: +34-987-293-554

\begin{abstract}
The aim of the present work is to verify the microstructural behavior of a B 521 tantalum alloy UNS Grade R05200 after welding, in relation to the welding thermal cycle. The joint design was a $1.5 \mathrm{~mm}$ thickness circumferential butt welding, on a $32 \mathrm{~mm}$ outside diameter pipe, welded in $1 \mathrm{G}$ position (horizontal, flat, and rotating). The chosen welding process was gas tungsten arc welding (GTAW). The microstructural analysis showed the presence of coarse, dendritic-columnar structures, as well as a hexagonal cell, with no cracks noted. Hardness tests showed an increase in hardness, from $120 \mathrm{HV}$ to $425 \mathrm{HV}$, in the heat-affected zone. Through finite element methods, the behavior of the temperature field was estimated and compared.
\end{abstract}

Keywords: tantalum welding; microstructure; heat-affected zone

\section{Introduction}

Tantalum is inherently a gray, soft, fabricable, and weldable metal that possesses a high hardness and melting temperature, $3269{ }^{\circ} \mathrm{C}$ (surpassed only by tungsten and rhenium), as well as excellent ductility (at lower temperatures). Its high melting point provides excellent characteristics for structural use at temperatures higher than other common refractory materials. Tantalum surpasses others, such as tungsten, with regard to fabricability, ductility, and weldability [1]. As a carbide (tantalum carbide), it is used as a graphite composite to attain even higher hardness and melting point of $3738^{\circ} \mathrm{C}$ [2].

Refractory metals have high melting points, density, and thermal conductivity [3]; its use has been extended in energy and space technology. One of the potential applications is the manufacturing (through welding processes) of heat exchangers for special applications that require high resistance to temperature or corrosion (ultra-corrosive or oxidizing applications). Those are usually considered difficult to weld, due to their great affinity with oxygen and other gaseous elements during the high temperature welding processes. Therefore, it cannot be welded if the heat or molten metal is exposed to the atmosphere. In general, impurities are avoided to prevent brittle compounds. The aim of this work is to deepen the knowledge of the welded joints microstructure in tube-to-tube joints, such as those potentially used for the manufacture of heat exchangers. To this end, it is intended to: (a) explore the existing bibliography to find the appropriate design of the welding process (always prevailing by its simplicity), (b) create a simplified model with finite element method that allow the microstructural results to be related to approximate temperature ranges, and (c) to carry out optical microscopy tests and mechanical tests in the molten and thermally-affected area of metal. Despite the abundance of bibliography, in 
reference to tantalum high alloys, with other elements such as aluminum or titanium, the welding of the metal itself has hardly been explored.

According to [4], in form of alloy, tantalum present as distinctive characteristics, the brittle-ductile transition. There is controversy about if BCC (body-centered cubic microstructure) pure tantalum exhibits or not a clear brittle-ductile transition. Recrystallization of the metal, during welding processes, can increase its transition temperature. Contamination during this high temperature period and the presence of metallic and non-metallic impurities can also induce the material brittleness. If such contamination occurs because the transition temperature is increased sufficiently, there will be a weld without desirable metallurgical characteristics. Tantalum has stable performance at room temperature, and when heated, it can be combined directly with non-metallic elements. When tantalum sheet heated to $200 \sim 300{ }^{\circ} \mathrm{C}$, micro-oxidation occurs $\left(\mathrm{O}_{2}, \mathrm{~N}_{2}, \mathrm{H}_{2}\right.$, and $\mathrm{C}$ enter interstitial spaces) and, when heated to above $500{ }^{\circ} \mathrm{C}$, rapid oxidation occurs [5].

Before welding, welding surface must be cleaned with chemical reagents and all traces of these products removed with water. After the parts are cleaned, they must be protected from oxidation using an inert gas or vacuum chamber $[5,6]$. Authors in [7] suggests that, during the tantalum welding process, filler material may or may not be used. Also recommends the use of direct current reverse polarity-electrode to positive (less heat input) and high frequency arc starter (improving the success rate of arc start). Helium as inert gas to maintain maximum penetration and counter the reverse polarity effect.

Tantalum can be welded to other metals [8], although with some of them it forms brittle intermetallic phases that must be avoided. Successful welding can be made with various techniques such as RW (resistance welding), GTAW (gas tungsten arc welding), PW (plasma welding), or EBW (electron-beam welding).

In previous studies [9] it was concluded that, when tantalum is under high temperature processes, it ignites in the air to form tantalum pentoxide, $\mathrm{Ta}_{2} \mathrm{O}_{5}$, a white and infusible substance that combines with metal oxides or hydroxides to form compounds called tantalates. Tanthalic acid, $\mathrm{TaO}_{5} \times \mathrm{H}_{2} \mathrm{O}$, is a gelatinous precipitate that is produced by humidity on tantalum pentachloride. When tantalum is heated on oxidizing atmospheres [10], the metal oxidizes to form different compounds. From about $250{ }^{\circ} \mathrm{C}$, a change in the color of the metal can be observed, this being first gray in color, then it acquires a yellow color, then bluish and finally a fine white powder indicative of the formation of the pentoxide. The different tonality is due to the variation in the thickness of the oxide layer formed. When the thickness of this oxidized layer is of the order of the wavelength of visible light, interferences are produced and colorations are observed.

According to [11], welding of tantalum causes considerable changes in the microstructure, both in the melting zone and in the heat-affected zone. In the melting zone, directionally oriented coarse grains are formed, which are characterized by the solidification behaviour and shape of the weld pool. In the heat-affected zone, there are continuous grain growth subject to heat gradients from the base metal to the melting zone boundary.

\section{Materials and Methods}

\subsection{Sample and Welding}

For the study, it is necessary to consider the characteristics of the material to be evaluated. Table 1 shows the standard physical properties of pure tantalum, assimilated in this work to those of the alloy B 52 (TBC), according to the Alloy Casting Institute (ACI). 
Table 1. Standard physical properties of pure tantalum.

\begin{tabular}{cc}
\hline Physical Properties & Ta \\
\hline Fusion temperature $(\mathrm{K})$ & 3269 \\
Vaporization temperature $(\mathrm{K})$ & 5698 \\
Density of solid metal $\left(\mathrm{kg} / \mathrm{m}^{3}\right)$ & 15,630 \\
Thermal conductivity of solid $(\mathrm{W} / \mathrm{m} \cdot \mathrm{K})$ & 57.5 \\
Thermal conductivity of liquid $(\mathrm{W} / \mathrm{m} \cdot \mathrm{K})$ & 66.5 \\
Specific heat of solid $(\mathrm{J} / \mathrm{kg} \cdot \mathrm{K})$ & 140 \\
Specific heat of liquid $(\mathrm{J} / \mathrm{kg} \cdot \mathrm{K})$ & 213 \\
Latent heat of melting $(\mathrm{kJ} / \mathrm{kg})$ & $1.7 \times 10^{5}$ \\
\hline
\end{tabular}

The chemical composition of B 521 (TBC) alloy is shown in Table 2. It is characterized by being high purity tantalum, which makes it a ductile alloy; it exhibits a behavior that is very sensitive to temperature and stress.

Table 2. Chemical composition of the B 521 tantalum alloy UNS Grade R05200.

\begin{tabular}{ccccccccccc}
\hline Grado & Fe & Si & Nb & W & Ti & $\mathbf{O}$ & $\mathbf{C r}$ & $\mathbf{H}$ & $\mathbf{N}$ & $\mathbf{T A}$ \\
\hline $\begin{array}{c}\text { B-521 } \\
\text { R05200 }\end{array}$ & 0.003 & 0.003 & 0.028 & 0.004 & 0.002 & 0.010 & 0.0005 & 0.001 & 0.002 & Balance \\
\hline
\end{tabular}

To perform the welded joint, three specimens of the tantalum alloys were prepared as butt joints with square edges of $1.5 \mathrm{~mm}$ thickness $\times 32 \mathrm{~mm}$ outside diameter pipes $(150 \mathrm{~mm}$ of length each of them). Figure 1 shows the schematic picture of the welding test samples. AWS standards suggest the use of the WT 2\% thorium tungsten electrode, as it has an oxide quantity between $1.7-2.2 \% \mathrm{ThO}_{2}$, which enhances arc ignition and reduces welding puddle contamination. Table 3 reproduces the welding characteristics and parameters.

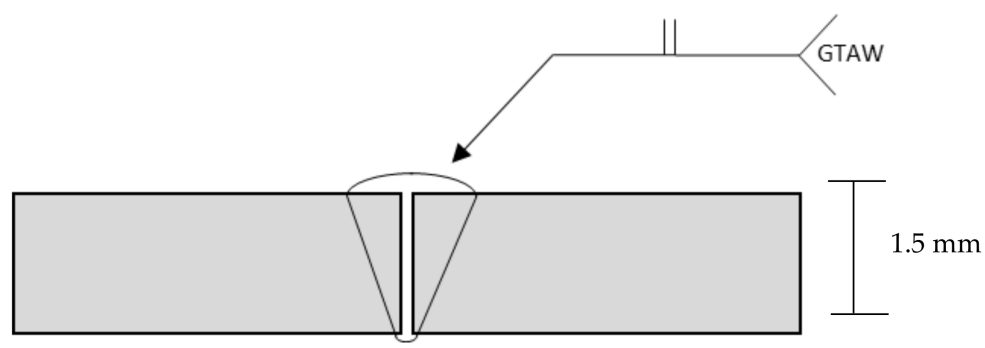

Figure 1. Schematic picture of the welding test samples.

Table 3. Welding characteristics and parameters.

\begin{tabular}{cc}
\hline Welding Characteristics and Parameters & - \\
\hline Welding Process & GTAW \\
Filler Material & No \\
Weld layers & 1 \\
Tungsten electrode diameter $(\mathrm{mm})$ & 1 \\
Length of the arc $(\mathrm{mm})$ & 2 \\
Voltage (V) & 11 \\
Intensity (A) & 73 \\
Welding speed (mm/min) & 56 \\
Pre-heating & No \\
Gas (ID-l/min) & Argon- \\
Use of backup & No \\
Welding Position & 1 G \\
Polarity & DCEN \\
Model of the w. machine & Lincoln Aspect 200 \\
\hline
\end{tabular}


The authors in [11] insist on special care with welding environment, pre-welding cleaning, and welding protection, due to the welding characteristics of tantalum materials. Strict technological measurements in cutting, groove processing, and GTAW process preparation were used to minimize the effect of foreign variables. No vacuum chamber was used. No current pulses were used during welding. Authors, such as [12], suggest a grain refinement process when temperatures in the melted pool decrease for a short time (to be raised again the next instant), creating nucleation by partial solidification.

\subsection{Microstructure}

The samples were cut on a horizontal lathe, guaranteeing abundant cooling (thus eliminating the burrs after cutting that could influence the quality of the metallographic preparation). Three samples, $15 \times 15 \mathrm{~mm}$ long and $1.5 \mathrm{~mm}$ thick, were cut and encapsulated (see Figure 2). These were polished and prepared according to the recommendation of E3-11 (Guide for Preparation of Metallographic Specimens) [13] and $\mathrm{Al}_{2} \mathrm{O}_{3}$ abrasive (1200 American National Standards Institute grit number), with rotation and etching with hydrofluoric acid (48\%) for $15 \mathrm{~s}$, as suggested by E407-07 Standard Practice for Microteaching Metals and Alloys [14].

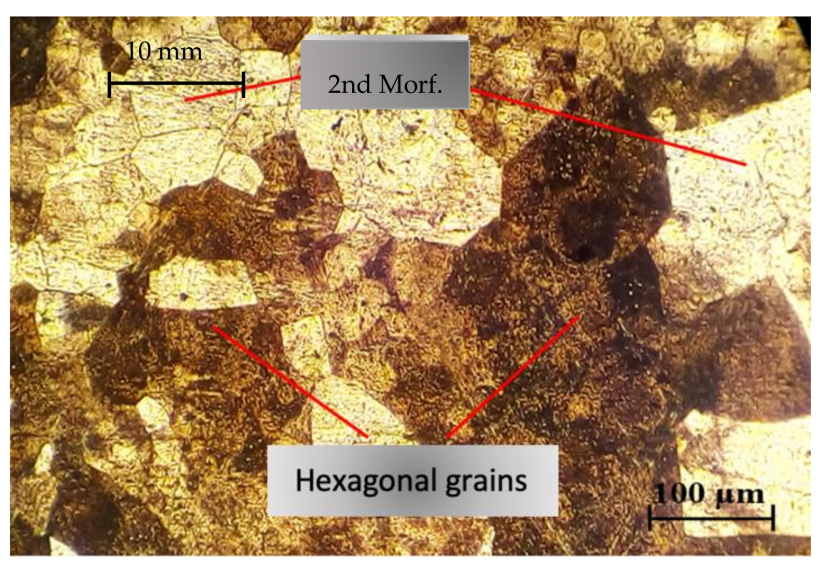

Figure 2. Standard sample of the tantalum alloy, extracted from the non-heat-affected zone.

A standard sample of the tantalum alloy, extracted from the non-heat-affected zone, was studied. The area was chosen to avoid any influence from the welding thermal cycle. Figure 2 shows a micrographic example of the inner structure. It was possible to identify two-phase grain morphologies, characteristic of the tantalum alloy as supplied, with the presence of large-sized, columnar, and hexagonal grains, regularly distributed throughout the matrix area.

The $\beta$-phase to $\alpha$-phase transformation of tantalum produces a unique microstructure with very unusual characteristics, especially for a crystalline material. The $\beta$-phase is also metastable and will transform to $\alpha$ when heated, from 750 to $775{ }^{\circ} \mathrm{C}$, as reported in [15].

\subsection{Finite Element Method Simulation}

For the design verification in this project, the finite element modeling was carried out using the ANSYS software (ANSYS ${ }^{\circledR}$ Academic Research Mechanical, Release 2015 R1 Washington County, PA, USA).

The arc welding process encapsulates several coupled physical phenomena, including, but not limited to, fluid flow in the molten pool, heat flow, and microstructural evolution of the materials. These processes must be modeled as a multiphysics problem.

Despite the fact that the thermomechanical coupling effects [16] are known to effect on the precision of the model (when considering the combined effect of temperature and mechanical stresses), it is preferred to opt for a purely thermal model. Other arc welding simulation techniques, such as the double ellipsoidal model, developed by [17], have been 
discarded to the difficulty of the determination of its geometric and energetic parameters. This mentioned author recommends determining the geometrical characteristics of the ellipsoid and calibrating the energy parameters experimentally.

Commercial FEA packages (such as ANSYS) are not capable of directly correlating the effects of multi-phase or -domain structures when the transformation of heterogeneous microstructures takes place (if a thermal and/or mechanical load is applied). In recent years, the phase field method, based on the Ginzburg-Landau theory [18], or isothermal phase field models [19] (for shape memory alloys) have been applied. It is understood that these simplifications suppose a slight uncertainty about the precision of the model, but they are understood as sufficient for the given purpose.

The physical properties of pure tantalum have been used to carry out the simulation, assuming that it is practically the same as that of the B 521 alloy (consider as high purity tantalum). For the boundary conditions, the actual temperatures were defined, and the restrictions considered applied, where, at the non-welded ends, the temperature is that of the environment. An orthohedral geometry was used on a square mesh configuration. Ten cells, of $0.2 \mathrm{~mm}$, were used in the direction of the $\mathrm{Z}$ axis (parallel to the heat-affected zone). Elements of $0.2 \mathrm{~mm}$ were used in the remaining areas. Figure 3 shows the meshed model of the welded pipe. The melting temperature of the base metal was applied to the welded area, which will allow for to obtain its distribution in the analyzed model. This more densely discretized the region concerns, from the vicinity of the surface to $1.5 \mathrm{~mm}$ in depth. The mesh was structured with 14,988 nodes and 2414 elements. SOLID186 elements were used; these are a higher-order, 3D, 20-node solid element that exhibits quadratic displacement behavior. The element is defined by 20 nodes, having three degrees of freedom per node: translations in the nodal $\mathrm{x}, \mathrm{y}$, and $\mathrm{z}$ directions [20].

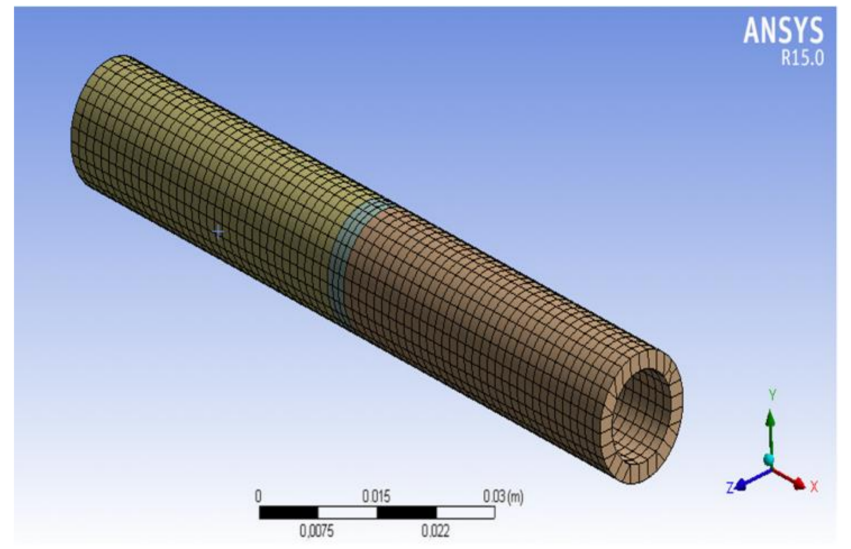

Figure 3. Meshed model of the welded pipe.

For the boundary conditions, the actual temperatures were defined, and the restrictions considered were applied. Displacement in X- "(direction transverse to the length of the weld bead), Y- (the outgoing direction of the weld plane), and Z-axis (direction parallel to the length of the weld bead) were suppressed. This is known as "restraining" the piece to be welded. For simplicity, a cylindrical projection with variation in the X-axis has been assumed.

The high temperatures of the refractory metal welding process did not allow the validation of the thermal model with thermocouples. Infrared thermometers show a good correlation, but the high degree of uncertainty at these temperatures is not conclusive, and the thermometer was focused on the bead area during the welding process. 


\section{Results}

\subsection{Microstructural Analysis in the Melted Metal Zone}

In the substrate of the melted zone (after welding), it is observed a high correlation between the orientations of the metallographic section, with respect to the cell growth. Figure 4 shows how the structure varies from a network of hexagonal cells to groups of lines almost parallel. The orientation of cells within a single metallic grain appears to be homogeneous. As the volume of the melted metal increased, the substructure became larger and misaligned, as a result of greater chemical segregation after the thermal welding cycle. The areas at the edges of the grains are probably caused by rapid cooling, since, in tantalum, the recrystallization temperature occurs in the range of $900-1200{ }^{\circ} \mathrm{C}$. A shear phenomenon can occur, and it is observed in the microstructures of the weld. The solute lines, representing the boundary zones between the molten filler metal and the solid, are continuous across the adjacent grain.

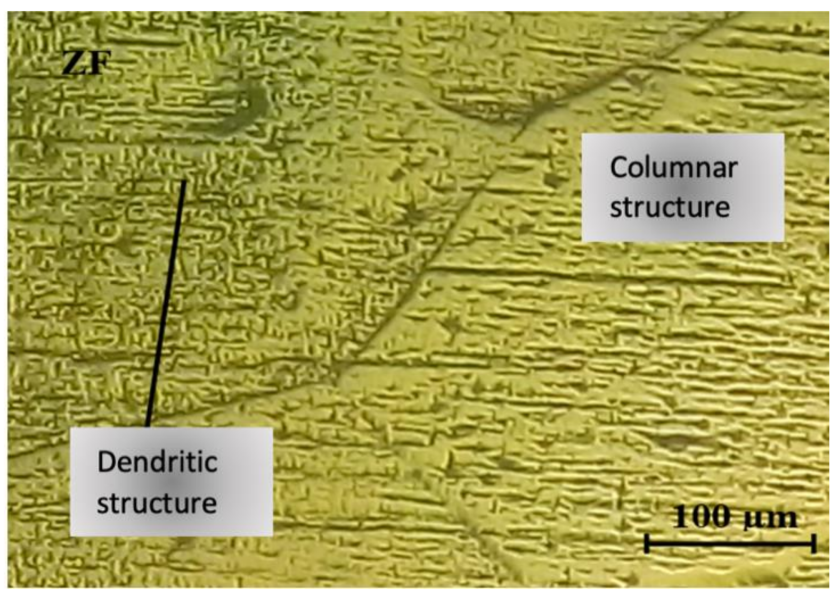

Figure 4. Welded metal zone micrography.

\subsection{Microstructural Analysis in the Heat Affected Zone}

Microstructural analysis of the base metal in the heat-affected zone, Figure $5 a, b$, to the left and right of the weld bead, shows the formation of coarse grains.

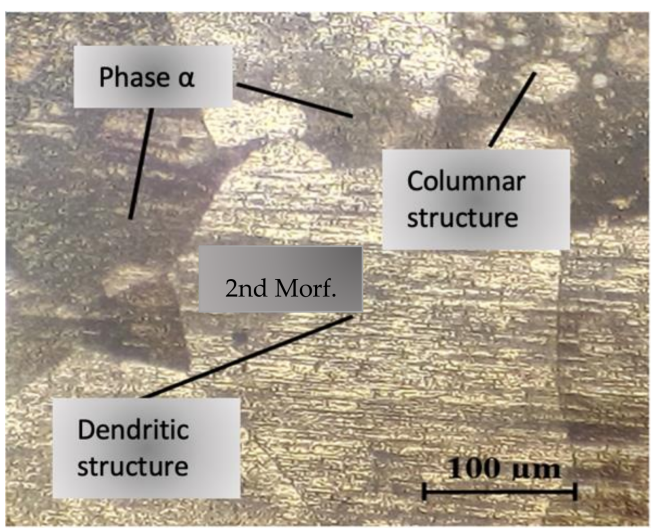

(a)

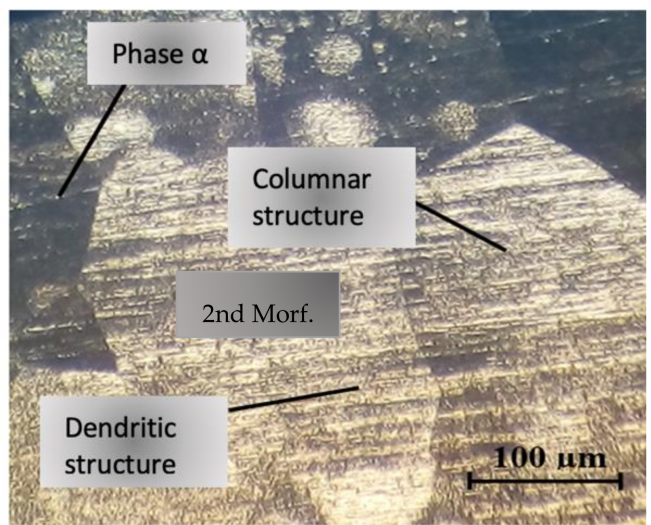

(b)

Figure 5. Heat affected zone micrography; (a) left side; (b) right side.

Figure 5a evidenced partially melted grains, with characteristics similar to that of the base metal and dominated by the development of a zone of columnar grains, as a result of the solidification of the weld pool. In the formation of this type of structure, the transition to equiaxed columnar grains is anomalous, unless the growth process is almost instantaneous. Within the cell grains, the formation of the dendritic structure can be observed. 
Figure $5 \mathrm{~b}$ also shows the formation of equiaxed grains, with the formation of fine second-phase precipitates, dispersed along the grain boundaries and within the grain. It can be seen that both structures (left and right) show no cracks or pores. We understand the columnar structure as a structure in which nucleation and growth, in a preferential direction, has dominated the process, while we understand the dendritic structure as a columnar structure so developed that the solidification-inducing force has driven the advance of the grain in branched directions.

The mechanical properties may be weaker in this zone than the rest of the structure, which is not thermally affected. This effect is produced by quenching or rapid cooling from temperatures above $1000{ }^{\circ} \mathrm{C}$, which has caused the occurrence of a massive transformation, although, in some cases, these properties can be improved by post-weld treatment. It is observed in both structures the epitaxial grain growth through the layers was observed and led to the formation of large, columnar grains and the development of strong texture.

\subsection{Microstructural Analysis of the Fusion Line Interface}

The interface of the fusion line shows a dendritic solidification pattern, the dendrites are present in the entire weld bead, epitaxial growth occurs in this area, following the solidification of the dendritic pattern, directed towards the electric arc heat source. In this zone, the grain structure can be controlled using methods that promote nucleation in the weld pool.

A line is observed in Figure $6 b$, where the base material is partially melted, since it is in direct contact with the pool (weld bead). In this line, a grain refinement is obtained, due to the thermal shock granted by the temperature of the weld. In both microstructures, the epitaxial growth of the grains is observed in a perpendicular way.

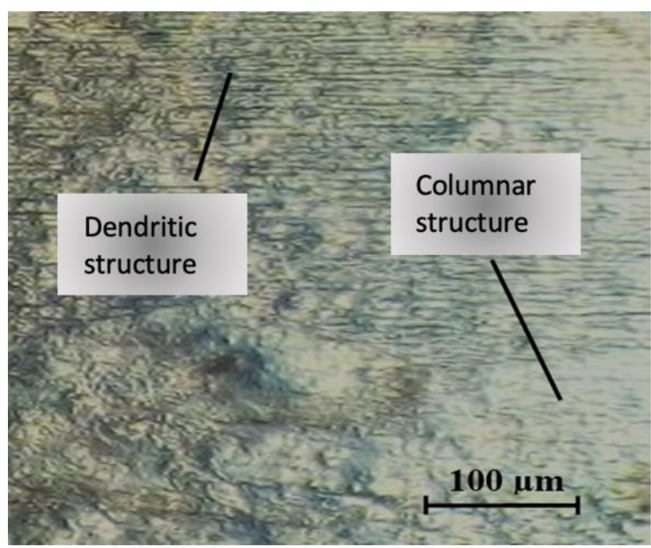

(a)

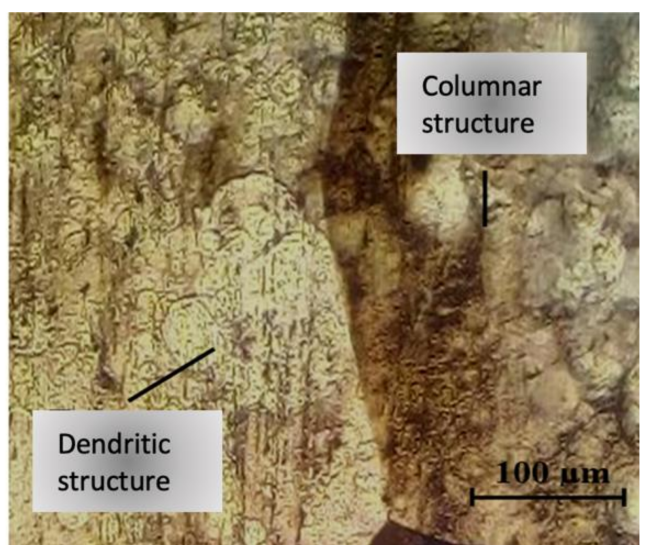

(b)

Figure 6. Fusion line micrography; (a) left side; (b) right side.

The microstructure of the base material is composed of polygonal grains that have not been modified by the thermal cycle (lower zone), however, the dendritic columnar morphology and the coarse columnar structure oriented towards the upper part of the weld bead and in the root was less pronounced, since the cooling rate was lower. In both microstructures, there has been a growth of columnar grains during solidification, formed parallel to the direction of the weld, presumably due to the occurrence of high temperatures in this area because the cooling rate is moderate. The transition area between the columnar and equiaxed structures was influenced by the composition of the heterogeneous mixture, by convection and by thermal gradients.

In both microstructures (Figure 6a,b), the epitaxial growth of the grains is observed in a perpendicular way. A line is observed (Figure 6b), where the base material is partially melted, since it is in direct contact with the pool (weld bead). In this line, a grain refinement is obtained, due to the thermal shock granted by the temperature of the weld. 


\subsection{Hardness}

Hardness measurements, according to ASTM E92 (Hardness Vickers 0.05) (2017) [21], were taken from the samples. Standardized Vickers indenters (Class B) were used with a load of $50 \mathrm{~g}$ (HV 0.05) and optical indentation measurement. No less than three measurements were done in every zone of interest, and the average value was used as an estimator. Table 4 shows the result and scheme. This evolution in hardness values is partially explained by the effect of grain size, especially the increase in the recrystallized zone (the heat-affected zone). However, the increase in hardness in the large grain size weld metal zone must be explained by the change in the proportion of the two observed morphologies. One characterized by less stable structures and heterogeneity and the other recrystallized, ductile, and, presumably due to the presence of nitrogen and oxygen, with a strong effect on hardness [22].

Table 4. Hardness results and scheme.

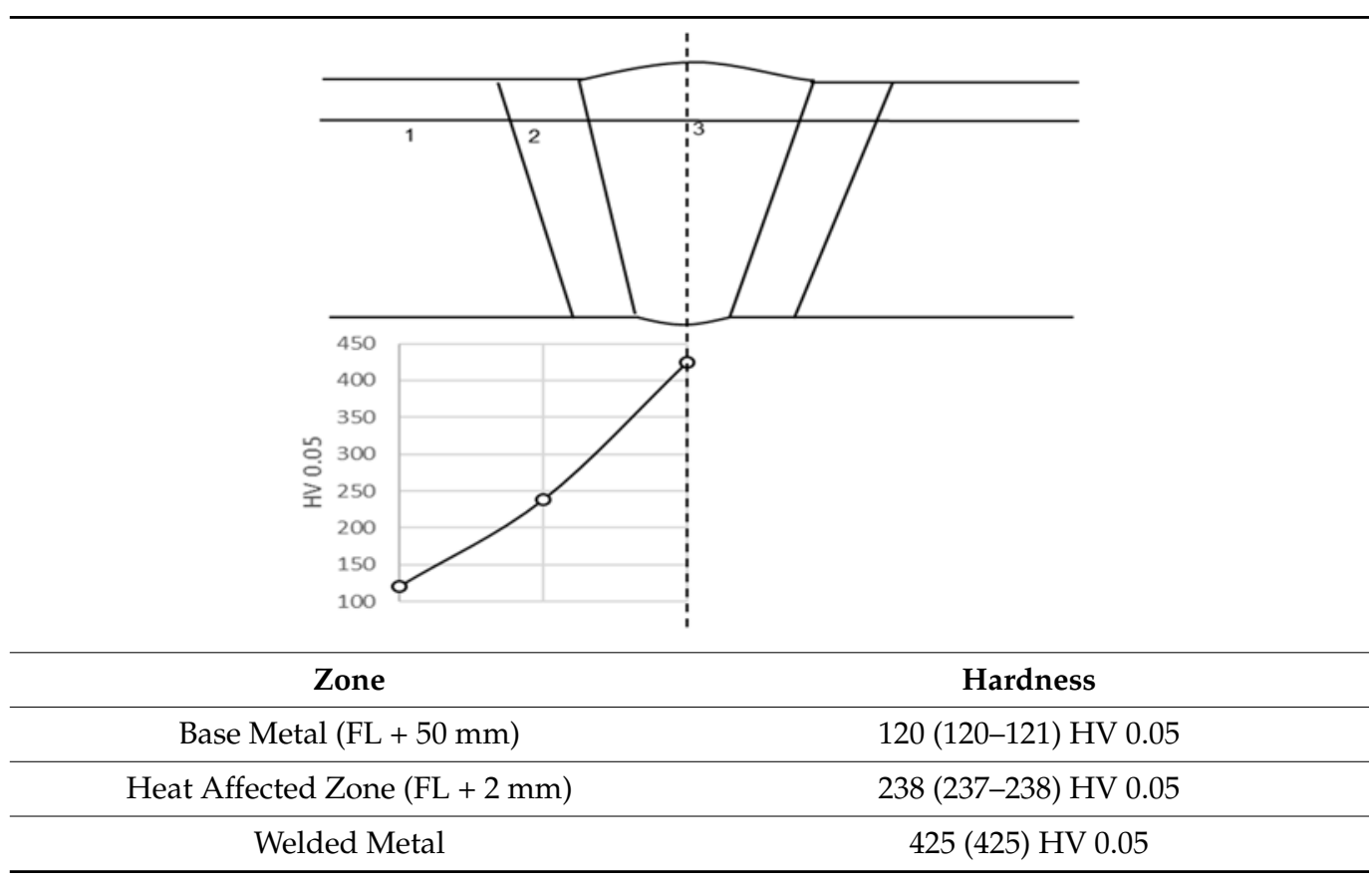

When correlating the oxygen content of the samples with the hardness, according to [22], it is found that the higher the oxygen content, the higher the resulting average hardness value; in particular, nitrogen and oxygen are strong hardeners of unalloyed tantalum, and the hardness of tantalum increased almost linearly with increasing oxygen content in the solid solution [23].

\section{Discussion}

\subsection{Weld Process Temperature Distribution}

Figure 7 shows the temperature distribution of the welding, as a transient non-linear process, in which thermal fields, distributed throughout the pipe, are obtained. 


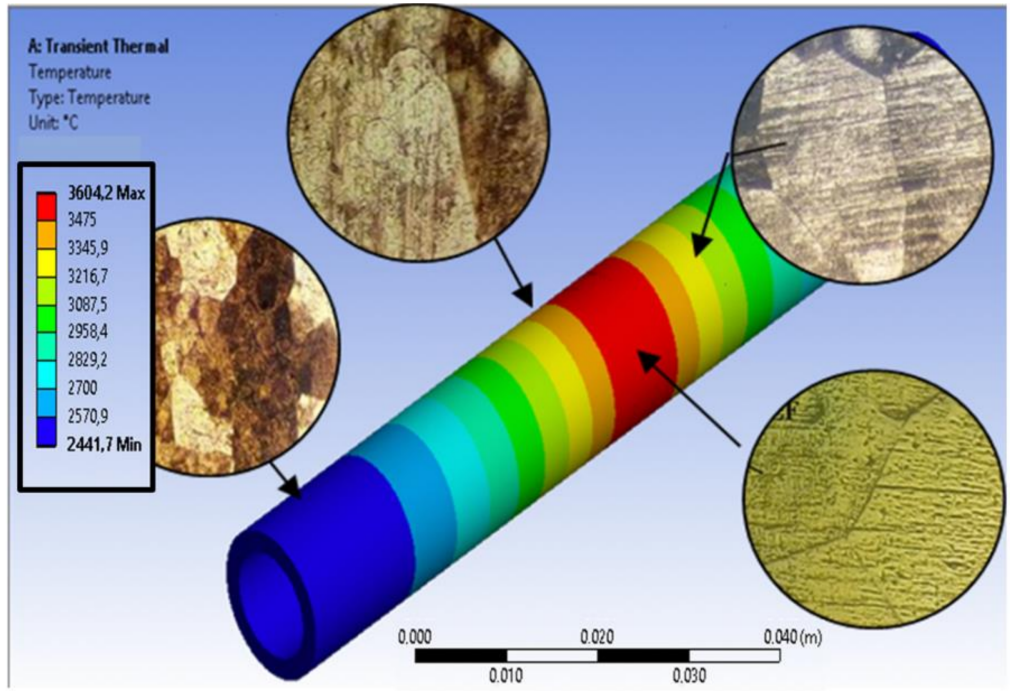

Figure 7. Temperature distribution and microstructure.

The obtained results correspond to the material deposition process, which establish the temperature evolution during the process, as well as the estimation of the risk of hot cracking of the tantalum alloy under the welding thermal cycle, due to the stresses generated.

It is observed that the temperature fields are temperature-dependent throughout the simulation process. The isotherms area is kept perpendicular to the axis of the seam, this is justified due to the transfers occurred by convection and radiation to the external environment.

The results show that the temperature is distributed over the entire diameter of the piece, from the maximum values (red color) to the minimum values (blue color). The material exhibits an elastoplastic behavior and its properties are temperature-dependent, with the dimension of the zone of thermal influence being approximately $40 \mathrm{~mm}$. This evolution of the temperature can lead to the remelting of the material and, in any case, a continuous change in the microstructure is induced during the entire process.

Visual inspection, non-destructive surface examinations (liquid penetrant test), flexural test, and micro-structural behavior confirmed its properties; no pores and a lack of fusion or cracks were evident in any of the analyzed areas, demonstrating the quality of the welding process performed.

\subsection{Temperature Evolution}

The thermal cycle represents how the temperature varies at any point during welding. The thermal history, at a given point, has a notable influence on the final microstructure of the metal and its mechanical properties. Figure 8 shows the temperature at the middle of the joint (green) and on an adjacent region (red). During the welding process, the area of the joint is heated sharply, in a localized way, and an evolution that, compared to the adjacent area, showed a non-uniform temperature distribution.

With regard to the state of stresses induced by the welding process, as the restrained zones, tensile stresses arise in the weld and heat-affected zones. Compressive stresses appear in distant zones, so that the equilibrium condition is fulfilled. The consequent contraction experienced is more incisive than in other nearby areas and, therefore, tensions are generated as soon as the heat source disappears.

On the other hand, when the heat input or the preheating temperature decreases, the distribution of maximum temperatures is concentrated on both sides of the weld bead, in two narrow bands. 


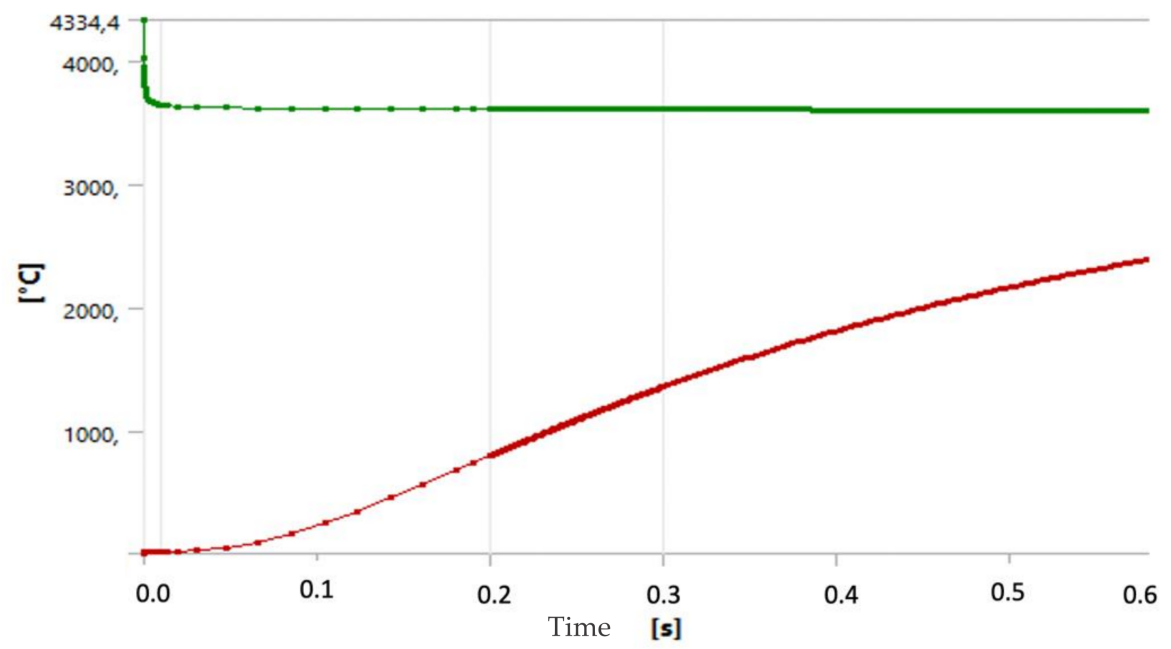

Figure 8. Temperature evolution for the middle of the joint and adjacent region fusion line $+50 \mathrm{~mm}$.

\subsection{Metallographic Study Correlation}

The different zones can be correlated with their particular thermal cycle, estimated through numerical simulation, taking into account the maximum temperature reached and residence time.

The different zones can be correlated with its particular thermal cycle, estimated by numerical simulation, taking into account the maximum temperature reached and residence time. Figure 9 is a metallographic study sketch (not-on-scale) to facilitate the microstructure evolution comprehension; it represents the microstructure observed on the previous images.

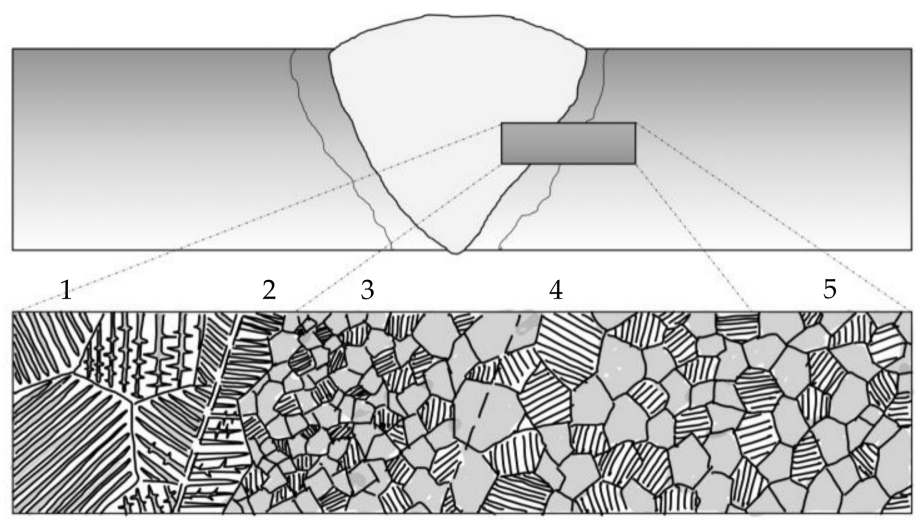

Figure 9. Metallographic study sketch (not-on-scale).

These variables affect the microstructure, state of recrystallization, and grain size. All in all, the microstructure, similarly, affect the hardness (estimator of mechanical resistance), ductility, corrosion resistance, and other mechanical properties of the welded joint important for this material. Table 5 shows the correlation among the microstructure, max. T. $\left({ }^{\circ} \mathrm{C}\right)$, and approximate time over $300{ }^{\circ} \mathrm{C}$. Figure 10 represents the thermal cycle after welding for the five zones, referred to in the previous table ( 1 melted metal, 2 fusion line, 3 recrystallization, 4 grain growth, and 5 "Base" metal). 
Table 5. Correlation thermal cycle microstructure.

\begin{tabular}{cccc}
\hline Zone (See Figure 8) & Max. T. $\left({ }^{\circ} \mathbf{C}\right)$ & Time $>\mathbf{3 0 0}{ }^{\circ} \mathbf{C}[\mathbf{s}]$ & Location \\
\hline (1) Melted metal & $<4334.4$ & 276 & Joint Point \\
(2) Fusion Line & $<3604.2$ & 258 & Fusion Line \\
(3) Recrystallization & $<1450$ & 221 & Fusion Line $+2 \mathrm{~mm}$ \\
(4) Grain growth & $<850$ & 186 & Fusion Line $+5 \mathrm{~mm}$ \\
(5) "Base" metal & $<300$ & 47 & Fusion Line $+50 \mathrm{~mm}$ \\
\hline
\end{tabular}

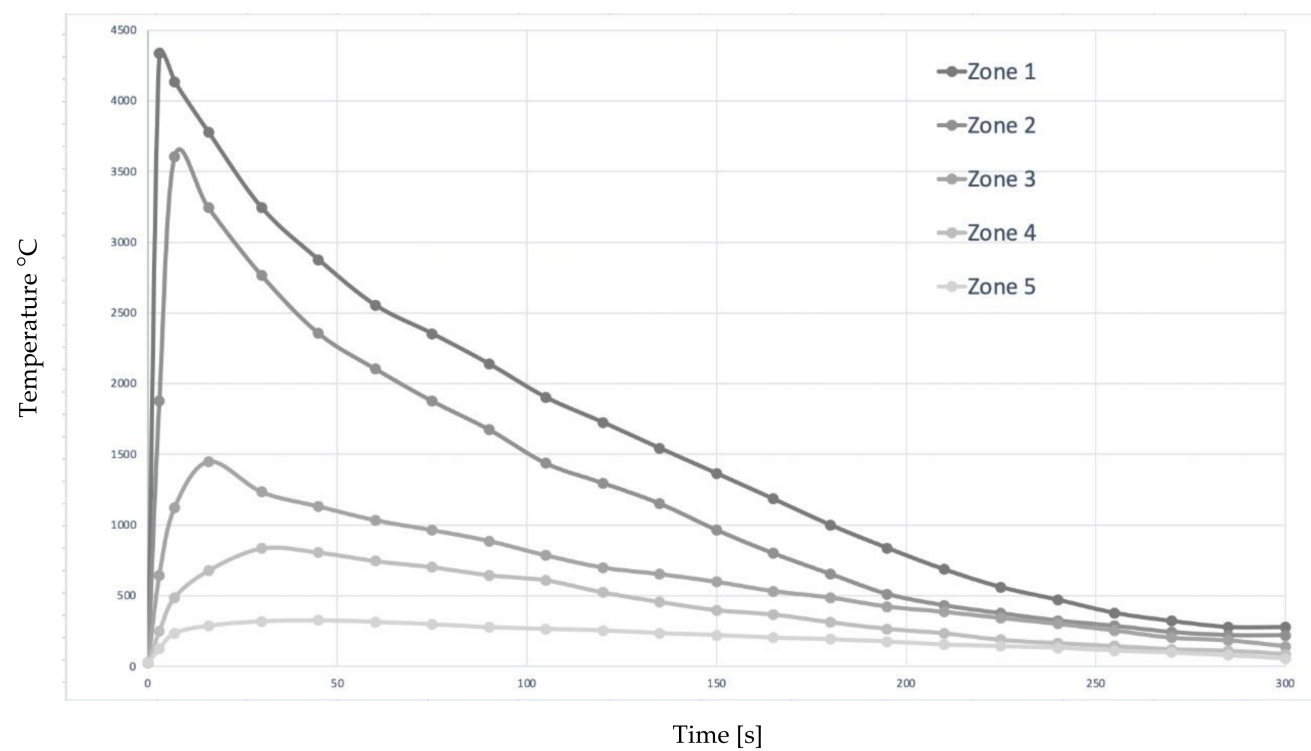

Figure 10. Cooling cycle after welding for the five zones referred to in Table 5.

\section{Conclusions}

The choice of welding process, parameters, and execution (based on bibliographic exploration) has produced a sound and flawless weld (no pores and lack of fusion or cracks). Visual inspection, surface non-destructive examinations (penetrant test), and bend-test confirmed its properties.

In the B 521 tantalum alloy UNS Grade R05200, metallurgical variations are observed in the different areas of the joint consisting of coarse columnar, and dendritic structures, as well as a network of hexagonal recrystallized cells, none of them prone to cracking.

It was determined that there is an increase in hardness from HV 120, in the base metal, to $237 \mathrm{HV} 0.05$ in the heat-affected zone to $425 \mathrm{HV} 0.05$ in the molten zone, which is the result of the microstructural transformations produced by the application of the thermal cycle and refractoriness of the tantalum alloy.

There is a relationship between the mechanical properties (in this case represented by the hardness value) and microstructure observed in the different zones. This microstructure can be related to the maximum temperature reached and residence time in different temperature ranges. Below the recrystallization temperature, the longer the high temperatures, the bigger the grain growth and more developed the dendritic structures.

Once the aforementioned relationship is confirmed, an interesting avenue of new studies is opened, which could involve the development of multiphysics simulation models, use of other simulation software, electron microscopy with a detection probem and more extreme welding parameters. 


\begin{abstract}
Author Contributions: Conceptualization, A.B.S., T.F.-C., I.R.-G. and L.S.T.; methodology, T.F.-C., I.R.-G., M.M.F. and L.S.T.; software, T.F.-C., I.R.-G., L.Á.d.P. and L.S.T.; validation, T.F.-C., I.R.-G. and L.S.T.; investigation, A.B.S., T.F.-C., I.R.-G., L.S.T., L.Á.d.P. and M.M.F.; resources, T.F.-C., I.R.-G. and L.S.T.; data curation, Á.P.V.; writing-original draft preparation, T.F.-C., I.R.-G. and L.S.T.; writingreview and editing, A.B.S., Á.P.V. and L.Á.d.P.; visualization, Á.P.V.; supervision, A.B.S. and Á.P.V.; project administration, A.B.S., L.Á.d.P. and M.M.F. All authors have read and agreed to the published version of the manuscript.
\end{abstract}

Funding: This research received no external funding.

Institutional Review Board Statement: Not applicable.

Informed Consent Statement: Not applicable.

Data Availability Statement: Data available on request due to restrictions.

Acknowledgments: We express our sincere gratitude to the University of Moa for their support and initiative, which has allowed for this project to be carried out.

Conflicts of Interest: The authors declare no conflict of interest.

\title{
References
}

1. Kammer, P.A.; Monroe, R.E.; Martin, D.C. Weldability of Tantalum Alloys. 1972. Available online: http://files.aws.org/wj/ supplement/WJ_1972_06_s304.pdf (accessed on 24 September 2021).

2. Climent, F.; Castella, G. Caracterización de la reacción de oxidación del tantalio a $\mathrm{Ta}_{2} \mathrm{O}_{5}$ mediante difracción de rayos $\mathrm{X}$ a alta temperatura, análisis térmico y microscopía electrónica de barrido. Bol. Soc. Esp. Cerám. Vidr. 1997, 36, 413-417.

3. Stelmakh, V.; Rinnerbauer, V.; Geil, R.; Aimone, P.; Senkevich, J.; Joannopoulos, J.; Soljačić, M.; Celanovic, I. High-temperature tantalum tungsten alloy photonic crystals: Stability, optical properties, and fabrication. Appl. Phys. Lett. 2013, $103,123903$. [CrossRef]

4. Greenberg, B.; Ivanov, M.; Patselov, A.; Besshaposhnikov, Y. The processes of fragmentation, intermixing and fusion upon explosion welding. AASRI Procedia 2012, 3, 66-72. [CrossRef]

5. Wang, C.; Hang, W. Introduction of tantalum lining pressure vessel. Technol. Wind 2018, 5, 124.

6. Hashim, F.; Salim, R.; Jaffar, M. On the spot brazing and spot soldering of tantalum. Acad. Res. Int. $2013,4,457-467$.

7. Grevey, D.; Vignal, V.; Issam, B.; Erazmus-Vignal, P.; Tomashchuk, I.; Dominique, D.; Sallamand, P. Microstructuraland microelectrochemical study of a tantalum-titanium weld interface. Mater. Des. 2015, 87, 974-985. [CrossRef]

8. Zhou, L.; Yuan, T.; Li, R.; Tang, J.; Wang, G.; Guo, K. Selective laser melting of pure tantalum: Densification, microstructure and mechanical behaviors. Mater. Sci. Eng. A 2017, 707, 443-451. [CrossRef]

9. Jakubowicz, J.; Adamek, G.; Sopata, M.; Koper, J.; Kachlicki, T.; Jarzebski, M. Microstructure and electrochemical properties of refractory nanocrystalline tantalum-based Alloys. Int. J. Electrochem. Sci. 2018, 13, 1956-1972. [CrossRef]

10. Tang, X. Phase transformations in Ti-Nb-Ta and Ti-Nb-Ta-Zr alloys. Mater. Sci. 2000, 35, 1805-1811. [CrossRef]

11. Xing, W.; Ye, J.L. Research on welding technology of tantalum cladding of Tantalum steel composite plate. Prog. Ti Ind. 2011, 28, 38-40.

12. Grill, A. Effect of current pulses on the temperature distribution and microstructure in TIG tantalum welds. Metall. Trans. B 1981, 12, 187-192. [CrossRef]

13. ASTM E3-11. In Standard Guide for Preparation of Metallographic Specimens; ASTM International: West Conshohocken, PA, USA, 2018.

14. ASTM E407-07. In Standard Practice for Micro-Etching Metals and Alloys; ASTM International: West Conshohocken, PA, USA, 2015.

15. Magnuson, M.; Greczynski, G.; Eriksson, F.; Hultman, L.; Hogberg, H. Electronic structure of $\beta$-Ta films from X-ray photoelectron spectroscopy and first-principles calculations. Appl. Surf. Sci. 2019, 470, 607-612. [CrossRef]

16. Franco, R.; Loaiza, G.; Lean, P.; Yépez, H. A one coupled thermo-mechanical model to determine residual stresses and deformations in butt welding of two ASTM A36 steel plates. In Proceedings of the VII International Conference on Computational Method for Coupled Problems in Science and Engineering, Rhodes Island, Greece, 12-14 June 2017. Available online: https:/ / upcommons.upc.edu/bitstream/handle/2117/190678/Coupled-2017-67-A\%20one\%20way\%20coupled.pdf (accessed on 17 November 2021).

17. Lindgren, L.E. Finite element modeling and simulation of welding. Part 2: Improved material modeling. J. Therm. Stress. 2001, 24, 195-231. [CrossRef]

18. Xi, S.; Su, Y. Phase Field Study of the Microstructural Dynamic Evolution and Mechanical Response of NiTi Shape Memory Alloy under Mechanical Loading. Materials 2021, 14, 183. [CrossRef] [PubMed]

19. Li, X.; Su, Y. A phase-field study of the martensitic detwinning in NiTi shape memory alloys under tension or compression. Acta Mech. 2020, 231, 1539-1557. [CrossRef]

20. ANSYS. Theory Reference. ANSYS Release 5.6, 11th ed.; ANSYS Inc.: Washington County, PA, USA, 1999. 
21. ASTM E92. In Standard Test Methods for Vickers Hardness and Knoop Hardness of Metallic Materials; ASTM International: West Conshohocken, PA, USA, 2017.

22. Puhr-Westerheide, J.; Elssner, G. On the solid solution hardening of tantalum by nitrogen and oxygen. J. Less-Common Met. 1970, 20, 371-374. [CrossRef]

23. Stecura, S. Observation of oxide particles below the apparent oxygen solubility limit in tantalum. Metall. Trans. 1974, 5, 1337-1340. [CrossRef] 